\title{
$\alpha$-Lipoic Acid Exerts Its Antiviral Effect against Viral Hemorrhagic Septicemia Virus (VHSV) by Promoting Upregulation of Antiviral Genes and Suppressing VHSV-Induced Oxidative Stress
}

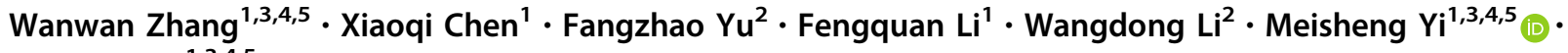 \\ Kuntong Jia ${ }^{1,3,4,5}$
}

Received: 17 April 2021 / Accepted: 28 June 2021 / Published online: 12 September 2021

(c) Wuhan Institute of Virology, CAS 2021

\begin{abstract}
Viral hemorrhagic septicemia virus (VHSV), belonging to the genus Novirhabdovirus, Rhabdoviridae family, is a causative agent of high mortality in fish and has caused significant losses to the aquaculture industry. Currently, no effective vaccines, Food and Drug Administration-approved inhibitors, or other therapeutic intervention options are available against VHSV. $\alpha$-Lipoic Acid (LA), a potent antioxidant, has been proposed to have antiviral effects against different viruses. In this study, LA $\left(\mathrm{CC}_{50}=472.6 \mu \mathrm{mol} / \mathrm{L}\right)$ was repurposed to exhibit antiviral activity against VHSV. In fathead minnow cells, LA significantly increased the cell viability post-VHSV infection $\left(\mathrm{EC}_{50}=42.7 \mu \mathrm{mol} / \mathrm{L}\right)$, and exerted a dose-dependent inhibitory effect on VHSV induced-plaque, cytopathic effects, and VHSV glycoprotein expression. The time-of-addition assay suggested that the antiviral activity of LA occurred at viral replication stage. Survival assay revealed that LA could significantly upregulated the survival rate of VHSV-infected largemouth bass in both co-injection (38.095\% vs. $1.887 \%$, $P<0.01)$ and post-injection manner $(38.813 \%$ vs. $8.696 \%, P<0.01)$ compared with the control group. Additional comparative transcriptome and qRT-PCR analysis revealed LA treatment upregulated the expression of several antiviral genes, such as IRF7, Viperin, and ISG15. Moreover, LA treatment reduced VHSV-induced reactive oxygen species production in addition to $N r f 2$ and $S O D 1$ expression. Taken together, these data demonstrated that LA suppressed VHSV replication by inducing antiviral genes expression and reducing VHSV-induced oxidative stress. These results suggest a new direction in the development of potential antiviral candidate drugs against VHSV infection.
\end{abstract}

Keywords Viral hemorrhagic septicemia virus (VHSV) $\cdot \alpha$-Lipoic acid (LA) $\cdot$ Antiviral $\cdot$ IFN response $\cdot$ Oxidative stress

Supplementary Information The online version contains supplementary material available at https://doi.org/10.1007/s12250021-00440-5.

\footnotetext{
Kuntong Jia

jiakt3@mail.sysu.edu.cn

$\triangle$ Meisheng Yi

yimsh@mail.sysu.edu.cn

1 School of Marine Sciences, Sun Yat-Sen University, Guangzhou 510275, China

2 Modern Agricultural Development Center of Zhuhai City, Zhuhai 519000, China

3 Southern Marine Science and Engineering Guangdong Laboratory (Zhuhai), Zhuhai 519000, China

4 Guangdong Provincial Key Laboratory of Marine Resources and Coastal Engineering, Guangzhou 510275, China

5 Pearl River Estuary Marine Ecosystem Research Station, Ministry of Education, Zhuhai 519000, China
}

\section{Introduction}

Viral hemorrhagic septicemia (VHS) is one of the most economically fish infectious diseases worldwide and is characterized by high morbidity and mortality. VHS has been reported to cause severe hemorrhages in fish eyes, mouth, fin and live tissues in a wide range of sea or fresh water cultured fishes, including rainbow trout (Hørlyck et al. 1984), turbot (Ross et al. 1995), and largemouth bass (Zhang et al. 2019). The aetiologic agent of VHS is viral hemorrhagic septicemia virus (VHSV), which is a negative-sense, single-stranded RNA enveloped virus, belonging to the genus Novirhabdovirus, Rhabdoviridae family (Schütze et al. 1999). The genome of VHSV contains six genes, encoding nucleoprotein $(\mathrm{N})$, phosphoprotein $(\mathrm{P})$, matrix protein $(\mathrm{M})$, glycoprotein $(\mathrm{G})$, nonvirion protein $(\mathrm{Nv})$, and polymerase (L). According to the OIE, VHSV 
has been listed as a reportable fish virus (http://www.oie. int/index.php?xml:id=171\&L=1\&htmfile=chapitre_dis eases_listed.htm), and no effective strategies against VHSV have yet to be developed.

Antiviral drugs and vaccines are two general strategies to combat viral infection. At present, various types of vaccines, such as whole-virus inactivated vaccines, attenuated vaccines, recombinant $G$ protein-based vaccines, and DNA vaccines, have been developed to prevent VHSV dissemination in laboratory tests, but they have not been used commercially for several reasons, including their safety, production costs, and mass production difficulty (Pereiro et al. 2016; Gomez-Casado et al. 2011). To overcome these drawbacks, antiviral drugs are highly desired in combating the threat of VHSV. Currently, some compounds have been demonstrated to have anti-VHSV activities in vitro or in vivo, such as EICAR (Moya et al. 2000), ribavirin (Marroqui et al. 2007), LJ001 (Balmer et al. 2018) and VER-155008 (Pham et al. 2019). Furthermore, many bioactive compounds showed various degrees of antiviral efficacy to VHSV, such as flavonoids (Kang et al. 2012), curcumin (Jeong et al. 2015), extracts of Celosia cristata, Raphanus sativus roots (Park et al. 2017) and algal Ecklonia cava (Yang et al. 2018).

$\alpha$-Lipoic acid (LA) is a disulfide-containing compound and acts as a cofactor for several enzymes participating in dehydrogenation and decarboxylation. As an essential biological antioxidant, LA has been reported to be involved in reactive oxygen species (ROS) scavenging, antioxidant recycling and metal chelating (Reed 1974; Hiller et al. 2016; Tibullo et al. 2017). For example, LA improves embryo development and protects against oxidative stress (Linck et al. 2007). Besides, LA also possesses many other biochemical functions, such as anti-inflammatory (Zhang and Frei 2001), anti-obesity (Miao et al. 2013), anticancer (Novotny et al. 2008), and antiproliferative effects (Selvakumar and Hsieh 2008). Due to its outstanding antioxidant capacity, LA has been used as an aquatic feed additive to enhance the detoxification and antioxidant capacity, thereby protecting the organism against oxidative stress in corydoras paleatus (Monserrat et al. 2008), pompano (Kütter et al. 2012), and pacu (Park et al. 2006).

Drug repositioning, also known as drug repurposing, is the process of assigning new indications for commercially available drugs other than the one(s) that they are originally intended (Pushpakom et al. 2019). Compared to traditional drug development, drug repurposing possesses multiple advantages, such as good safety and well-known pharmacokinetic and pharmacodynamics properties, which reduce the risk of failure to an extreme (Bloom 2015). Thus, drug repurposing has been considered to be a practical and economical approach for drug development since emerging in the early 1990s (Kesselheim et al. 2015; Hernandez et al. 2017; Novac 2013). Especially, drug repurposing played an important role in combating rapidly spreading viral infectious diseases. Up to now, several clinically approved drugs have been proved to be potential broadspectrum antivirals through drug repurposing. For example, rilpivirine, a clinically approved human immunodeficiency virus (HIV) drug, was identified as a Zika virus (ZIKV) inhibitor by targeting ZIKV RdRp (Sariyer et al. 2019). Chlorpromazine hydrochloride, a widely used antipsychotic, was found to be effective at inhibiting either Middle East respiratory syndrome coronavirus or severe acute respiratory syndrome coronavirus (SARS-CoV) infection (Dyall et al. 2014).

To identify potential compounds with anti-VHSV activity, in this study, a library of 50 kinds of Food and Drug Administration (FDA) approved drugs, having antiviral activity against a series of other viruses, was screened for antiviral activity against VHSV. We found that LA was effective at inhibiting VHSV infection. Furthermore, we characterized the mechanism by which LA affected VHSV infection. Our results showed that LA had the potential to be developed as an effective anti-VHSV drug.

\section{Materials and Methods}

\section{Cells, Compounds and Virus}

Fathead minnow (FHM) cells were grown in Medium 199 (M199, Gibco, Grand Island, NY, USA) supplemented with $10 \%$ fetal bovine serum (FBS, Gibco, Carlsbad, CA, USA). The cell culture was maintained in an incubator at $28{ }^{\circ} \mathrm{C}$ without $\mathrm{CO}_{2}$ supplement.

An antiviral compound library consisted of 50 antiviral compounds (Supplementary Table S1), including LA (Cat \#HY-N0492), was purchased from Med Chem Express (MCE, USA). Each compound was dissolved in dimethyl sulfoxide (DMSO, Sigma-Aldrich, St. Louis, MO, USA) and stored at $-80^{\circ} \mathrm{C}$. The stock solution was further diluted with M199 (FBS free), with the final concentration of DMSO less than $0.1 \%$. Elesclomol, an oxidative stress inducer, was purchased from MCE (Cat \#HY-12040) and dissolved in DMSO.

VHSV-LB2018 (IVa) was isolated from a wild largemouth bass in the Pearl River and kept in our laboratory (Zhang et al. 2019). VHSV was propagated in FHM cells at $28{ }^{\circ} \mathrm{C}$. The virus titers, detected by $50 \%$ tissue culture infective dose $\left(\mathrm{TCID}_{50}\right)$, reached $10^{7.5} \mathrm{TCID}_{50} / \mathrm{mL}$. 


\section{Antiviral Activity Screening}

FHM cells were seeded in 96-well plates, at a density of $2 \times 10^{4}$ cells per well $24 \mathrm{~h}$ prior to the experiment. Firstly, the cytotoxicity of compounds was tested in FHM cells. Cells were incubated with serial diluted compounds or DMSO at $28{ }^{\circ} \mathrm{C}$ for $48 \mathrm{~h}$. The maximum safe dosage, which did not cause cellular damage, was chosen for further screening. Then, VHSV and compounds were inoculated to FHM monolayers simultaneously in triplicate wells. After $48 \mathrm{~h}$, the antiviral activity was evaluated by cytopathic effect (CPE).

\section{Cell Viability Assay}

Cell viability assay was performed to determine $50 \%$ cytotoxicity $\left(\mathrm{CC}_{50}\right)$ of LA and the median effective concentration $\left(\mathrm{EC}_{50}\right)$ of LA against VHSV by using Cell Counting Kit-8 reagent (CCK-8, MCE, Cat \#HY-K0301). For $\mathrm{CC}_{50}$ calculation, FHM cells were seeded in 96-well plates and incubated with LA at concentrations of 10, 20, $30,50,100,200,400$ or $800 \mu \mathrm{mol} / \mathrm{L}$. After incubation for $48 \mathrm{~h}$ at $28{ }^{\circ} \mathrm{C}$, the cells were washed with PBS for 3 times, then incubated with the fresh M199 (2\% FBS) diluted CCK-8 solution $(10 \mu \mathrm{L})$ for $2 \mathrm{~h}$. The experiment was conducted three times in quadruplicate (4 wells in 96 wells) for each concentration of the compound. Cell viability was measured through the absorbance at $450 \mathrm{~nm}$ and calculated out using [Inhibitor] vs. response -Variable slope (four parameters) algorithms in GraphPad Prism 8.0.2.

For the cell protection assay, FHM monolayers were inoculated with M199 (2\% FBS) containing VHSV and predetermined concentration of compounds or DMSO for $48 \mathrm{~h}$. The experiment was conducted three times in quadruplicate. The $\mathrm{EC}_{50}$ was calculated out using [Agonist] vs. response-Variable slope (four parameters) algorithms in GraphPad Prism 8.0.2.

\section{Cell Plaque Assay}

FHM cells were seeded into 24-well plates and cultured at $28{ }^{\circ} \mathrm{C}$ to obtain $90 \%$ confluence. Then the growth media was replaced with fresh M199 (2\% FBS) and treated with VHSV and different concentrations of LA for $36 \mathrm{~h}$. Finally, the cells were fixed and stained using $0.1 \%$ crystal violet solution, the plaque induced by VHSV was observed using an inverted microscope.

\section{Antiviral Activity Assay}

A time-of-addition experiment was performed by treating FHM cells with VHSV $\left(10^{1.5} \mathrm{TCID}_{50}\right)$ and LA $(50 \mu \mathrm{mol} / \mathrm{L})$ in different manners. Ribavirin $(8 \mu \mathrm{mol} / \mathrm{L}$, MCE, Cat \#ICN-1229) was used as the positive control, DMSO was the negative control. In the co-exposure experiment, compound and VHSV were both incubated with cells. In the pre-exposure experiment, the cells were pretreated with compound for $4 \mathrm{~h}$ followed by VHSV infection. In the post-exposure experiment, the compound was added at $4 \mathrm{~h}$ post-infection (hpi). The above incubations were carried out at $28{ }^{\circ} \mathrm{C}$. Cells were collected at 24 and 36 hpi for qRTPCR analysis.

\section{RNA Extraction and qRT-PCR Analysis}

Total RNA was extracted using Trizol reagents (Invitrogen, Carlsbad, CA, USA), and reverse-transcribed into firststrand cDNA using a reverse transcription Mix (Promega, Madison, WI, USA). Viral gene expression level in FHM cells was determined by qRT-PCR targeting a partial region of VHSV $G$ or $N$ gene. Primers are presented in Supplementary Table S2. qRT-PCR amplification was carried out using the LightCycler 480 II (Roche, Mannheim, Germany) with cycling conditions as follows: $95{ }^{\circ} \mathrm{C}$ for $30 \mathrm{~s}, 40$ cycles of $95{ }^{\circ} \mathrm{C}$ for $15 \mathrm{~s}, 60^{\circ} \mathrm{C}$ for $15 \mathrm{~s}$ and $72{ }^{\circ} \mathrm{C}$ for $15 \mathrm{~s}$. A melting curve analysis was conducted to verify the specificity of the amplified product. All experiments were conducted at least three times. Data from qRT-PCR were analyzed using $2^{-\Delta \Delta C t}$ method and shown as mean \pm standard deviation.

\section{Virus Binding Assay}

FHM cells in 12-well plates were incubated with M199 containing VHSV $\left(10^{1.5} \mathrm{TCID}_{50}\right)$ in the presence of LA $(50 \mu \mathrm{mol} / \mathrm{L})$, ribavirin $(8 \mu \mathrm{mol} / \mathrm{L})$ or DMSO at $4{ }^{\circ} \mathrm{C}$ for $2 \mathrm{~h}$ to complete virus binding but not internalization. Unbound virus particles were removed by washing cells with PBS three times and renewing M199. The cells were cultured at $28{ }^{\circ} \mathrm{C}$ for another $22 \mathrm{~h}$, the viral gene expression in cells was analyzed by qRT-PCR subsequently.

\section{Virus Internalization Assay}

FHM cells were incubated with M199 containing VHSV at $4{ }^{\circ} \mathrm{C}$ for $2 \mathrm{~h}$. After removing the unbound virus by three times of washing with PBS, the cells were incubated in fresh M199 with LA, ribavirin or DMSO at $28{ }^{\circ} \mathrm{C}$ for $2 \mathrm{~h}$ to facilitate virus internalization. Then the cells were washed with PBS to remove the compounds and further cultured at $28{ }^{\circ} \mathrm{C}$ for another $20 \mathrm{~h}$. The samples were analyzed by qRT-PCR subsequently. 


\section{Viral Gene Replication Assay}

FHM cells were infected with VHSV at $4{ }^{\circ} \mathrm{C}$ for $2 \mathrm{~h}$. After washing with PBS three times, the cells were replenished with fresh M199. After $2 \mathrm{~h}$ culture, the cells were incubated with LA, ribavirin or DMSO for $4 \mathrm{~h}$, followed by collection for qRT-PCR analysis.

\section{Survival Assay}

Largemouth bass (Micropterus salmoides), approximately $5 \mathrm{~cm}$ in body length, was purchased from a fish farm in Zhuhai city, Guangdong, China. Fish was acclimated for 7 days before the experiment.

The survival rate was calculated in healthy largemouth bass. Largemouth bass was divided into five groups: the PBS negative control, VHSV co-exposed with DMSO, VHSV co-exposed with LA $(25 \mu \mathrm{mol} / \mathrm{L})$, VHSV postexposed with DMSO at $4 \mathrm{hpi}$, and VHSV post-exposed with LA $(25 \mu \mathrm{mol} / \mathrm{L})$ at $4 \mathrm{hpi}(\mathrm{n}=50)$. Each largemouth bass was injected with $20 \mu \mathrm{L}$ of VHSV $\left(10^{1.5} \mathrm{TCID}_{50}\right)$ with intraperitoneal injection, separately. The survival rate of each group was recorded every half-day by counting the numbers of largemouth bass. The differences between groups were analyzed with the log-rank test method using GraphPad Prism 8.0.2.

\section{Transcriptome Analysis}

FHM cells were grown in $25 \mathrm{~cm}^{2}$ dishes. LA or DMSO was inoculated into FHM monolayers with VHSV $\left(10^{2.8} \mathrm{TCID}_{50}\right)$ for $24 \mathrm{~h}$ at $28{ }^{\circ} \mathrm{C}$. Total RNAs of FHM cells were extracted and determined using NanoDrop 2000 UV-Vis Spectrophotometer for RNA-sequencing and transcriptome analysis by GENE DENOVO corporation.

\section{Measurement of Intracellular ROS Production}

The intracellular ROS level was measured using a Reactive Oxygen Species Assay Kit (Beyotime Biotechnology, Guangzhou, China). Briefly, FHM cells in 12-well plates were treated with VHSV $\left(10^{1.5} \mathrm{TCID}_{50}\right)$ or PBS (negative control). The mock group was untreated, the positive control group was treated with Rosup according to the manufacturer's instructions. Following the treatment, cells were washed with PBS and incubated with $10 \mu \mathrm{mol} / \mathrm{L}$ oxidation-sensitive fluorescent probe (DCFH-DA) at $37{ }^{\circ} \mathrm{C}$ for $30 \mathrm{~min}$ in dark to detect the intracellular ROS production. The green fluorescence was observed using fluorescence microscopy (Olympus, Hamburg, Germany) under the following band-pass filters: 488-nm excitation and 515-nm long-pass filter.
To detect the effect of LA on VHSV-induced ROS production, FHM cells were infected with VHSV and treated with DMSO or LA $(50 \mu \mathrm{mol} / \mathrm{L})$ in pre-, co- or postexposure manner for $24 \mathrm{~h}$. The intracellular ROS production was detected as above.

\section{Data Analysis}

Statistical significance was determined by one-way ANOVA algorithm using Graphpad Prism. $P<0.05$ was considered to be statistically significant.

\section{Results}

\section{Initial Antiviral Screening of 50 FDA-Approved Drugs against VHSV}

To identify potential antiviral compounds against VHSV, the anti-VHSV activity of 50 FDA-approved drugs was evaluated at a fixed concentration of $30 \mu \mathrm{mol} / \mathrm{L}$ using CPE-based screening assay in FHM cells. Ribavirin, a previously identified antiviral compound, was used as a positive control (Kamiyama et al. 2017). As shown in Fig. 1, LA showed strong inhibitory activity against VHSV-induced CPE at the concentration of $30 \mu \mathrm{mol} / \mathrm{L}$ without significant cytotoxicity $\left(\mathrm{CC}_{50}\right.$ values of $472.6 \mu \mathrm{mol} / \mathrm{L}$ for LA) (Fig. 1). These results indicated that LA had a potential anti-VHSV activity, thus was selected for the following studies.

\section{Antiviral Efficacy of LA against VHSV}

To further confirm and evaluate the antiviral activity of LA, the cell viability, virus-induced plaque, CPEs and expression level of viral genes were assessed. First, the $\mathrm{EC}_{50}$ values for LA were inferred by calculating the percentage of virus-infected cells. As shown in Fig. 2A, LA dose-dependently increased the cell viability of VHSV infected FHM cells, resulting in an $\mathrm{EC}_{50}$ value of $42.7 \mu \mathrm{mol} / \mathrm{L}$. Moreover, crystal violet staining indicated VHSV-induced plaques were significantly decreased at $36 \mathrm{~h}$ post LA treatment in a dose-dependent manner at concentrations ranging from 30 to $50 \mu \mathrm{mol} / \mathrm{L}$ (Fig. 2B). These results suggested that LA was a potential inhibitor of VHSV in vitro.

In parallel to the inhibition efficiency, the anti-VHSV activity of LA was assessed in more detail through a timeof-drug-addition experiment. LA was added to FHM cells at $4 \mathrm{~h}$ before infection (pre-exposure), following the virus inoculation (co-exposure) or $4 \mathrm{~h}$ after infection (postexposure), respectively (Fig. 2C). As shown in Fig. 2D, typical severe CPEs, consisting of rounder clusters, were 
Fig. 1 Compound screening model and cytotoxicity of $\alpha$ Lipoic Acid (LA) on FHM cells. The cytotoxicity of LA was examined in FHM cells using Cell Counting Kit-8 (CCK-8). The median cytotoxic concentration $\left(\mathrm{CC}_{50}\right)$ was calculated in GraphPad Prism 8.0.2.

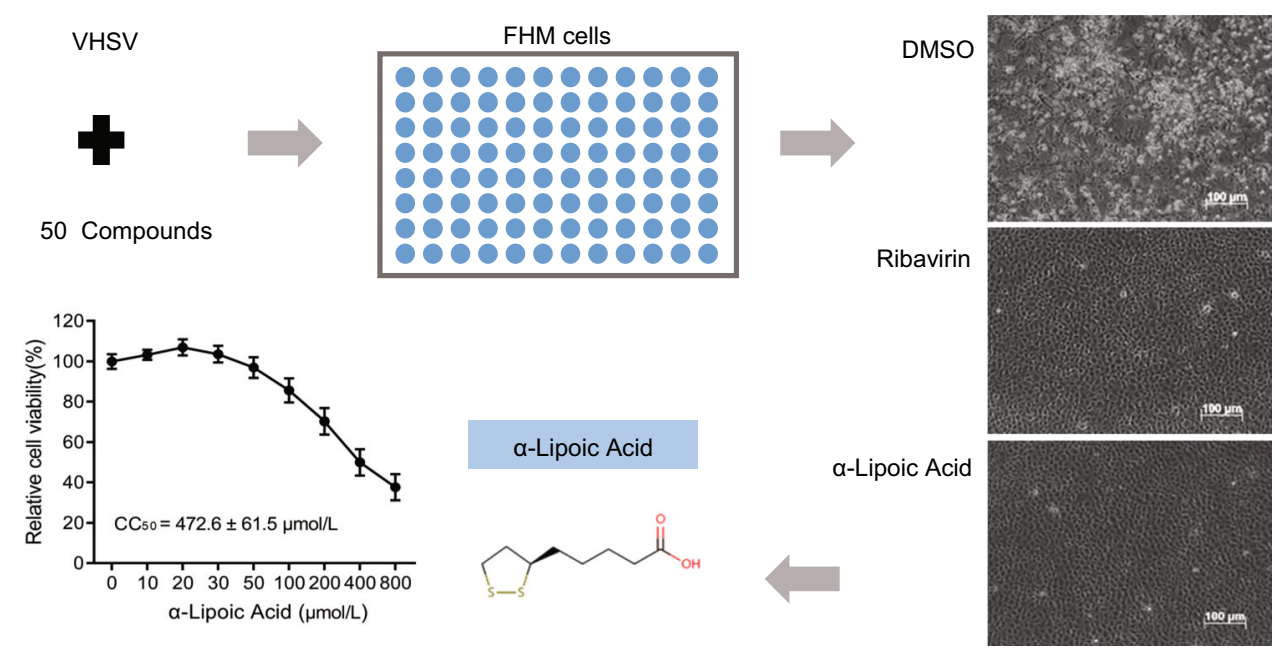

observed in DMSO-treated cells under all experimental conditions. Notably, LA significantly reduced the CPEs induced by VHSV infection at 36 hpi. Moreover, the antiviral activity of LA was further verified by detecting the expression of VHSV $G$ mRNA. As shown in Fig. 2E, LA significantly inhibited the increase of $G$ mRNA levels in comparison with DMSO treated and VHSV infected FHM cells in pre-exposure, co-exposure and post-exposure assays, and LA showed an antiviral effect similar to the known antiviral drug ribavirin. Collectively, these results confirmed LA could reduce the infectivity of VHSV at different treatment times.

\section{LA Inhibits Viral Replication but Not Entry}

To determine which step of the VHSV infection cycle was affected by LA, we explored the antiviral effect of LA on virus attachment, internalization, and gene replication stages by a time-of-drug-addition assay. FHM cells were infected with VHSV with the presence of LA at indicated times, respectively (Fig. 3A). As shown in Fig. 3B and 3C, the attachment and internalization of VHSV were not affected by LA treatment. LA significantly decreased the mRNA level of VHSV $G$ gene in FHM cells treated with LA at $4 \mathrm{hpi}$, indicating the replication of VHSV was inhibited by LA treatment (Fig. 3D). Moreover, the survival rate of largemouth bass co-injected with LA and VHSV was significantly higher than that of the DMSO and VHSV injected group $(38.095 \%$ vs. $1.887 \%, P<0.01)$ (Fig. 3E). In addition, the survival percent in largemouth bass injected with VHSV for $4 \mathrm{~h}$ prior to injection of LA showed a highly significant enhancement in comparison with that of the control group $(38.813 \%$ vs. $8.696 \%$, $P<0.01$ ) (Fig. 3F).

\section{LA Treatment Induces Upregulation of Antiviral Genes}

To dissect the biological mechanism of LA-mediated VHSV inhibition, we examined the effect of LA on cell immune response through RNA-sequencing assay on DMSO and LA-treated FHM cells with VHSV infection (NCBI Sequence Read Archive under BioProject number: PRJNA715306). Comparative transcriptome analysis showed that 2262 up-regulated genes and 3257 downregulated genes were identified in LA-treated cells compared with DMSO treatment. GO enrichment assigned 2994 differentially expressed genes (DEGs) to biological process (BP), 1574 to cellular component (CC) and 951 to molecular function (MF). For BP, 340 unigenes belonging to the cellular process were up-regulated in LA-treatment group. For $\mathrm{CC}$, the most up-regulated genes were assigned to cell and cell part with 224 unigenes. For MF, 272 unigenes associated with binding were highly up-regulated (Fig. 4A). Among which, a majority of DEGs involved in antiviral response were significantly up-regulated, such as PKR, Trim25, IFI27 2a/b, IRF2/3/5/7, Mx2, IFN1, ISG15, Viperin, Mxra7, DDX21/46, TRIM8, STAT1/2, TBK1, TRAF2/3/4, TLR18, JAK2 and so on (Fig. 4B).

Furthermore, the transcriptional levels of IFN1, IRF3, IRF7, ISG15, Viperin and PKR were analyzed by qRTPCR. As shown in Fig. 4C-4H, IRF3, IRF7, Viperin, ISG15, IFN1 and PKR exhibited 2.5-, 22-, 47-, 21-, 2.3and 1.5-fold increases under LA treatment compared with DMSO control. Meanwhile, post LA and VHSV costimulation, those genes also exhibited 1.5-, 6-, 18-, 16-, 1.7- and 1.4-fold increases compared with the control group, which was almost in accordance with the high throughput sequencing data. These results indicated that the anti-VHSV effect of LA was partial dependent of the activation of antiviral genes. 


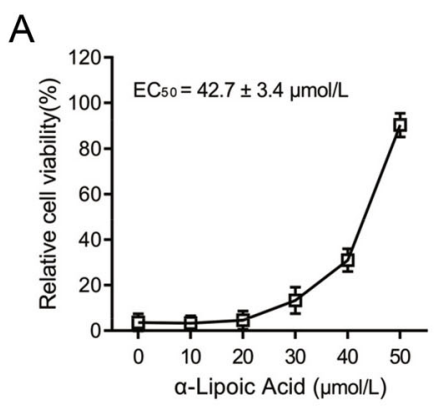

D

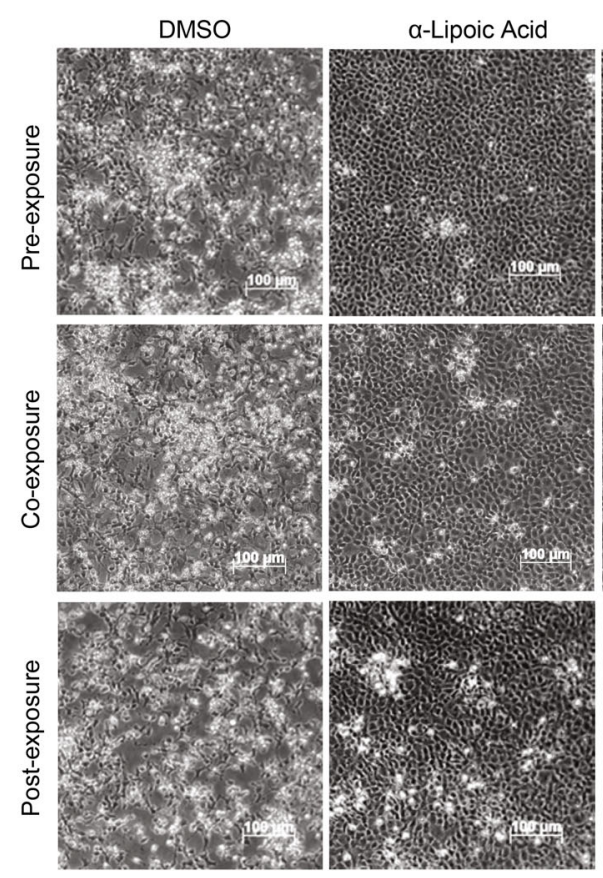

B

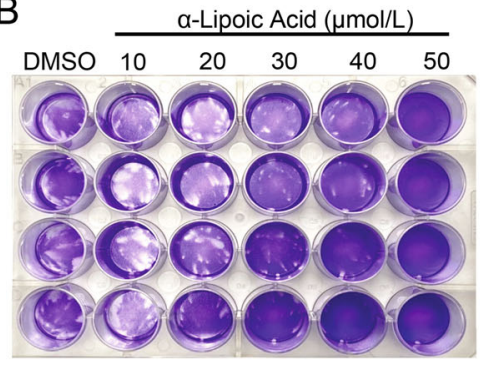

C

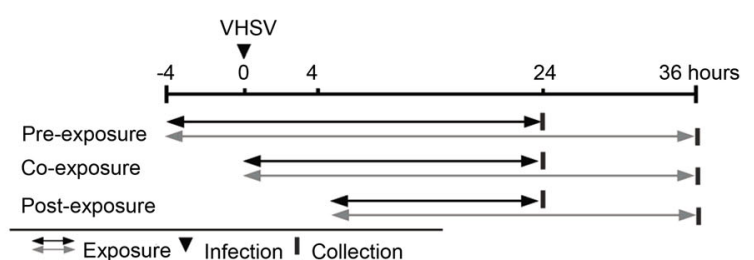

E
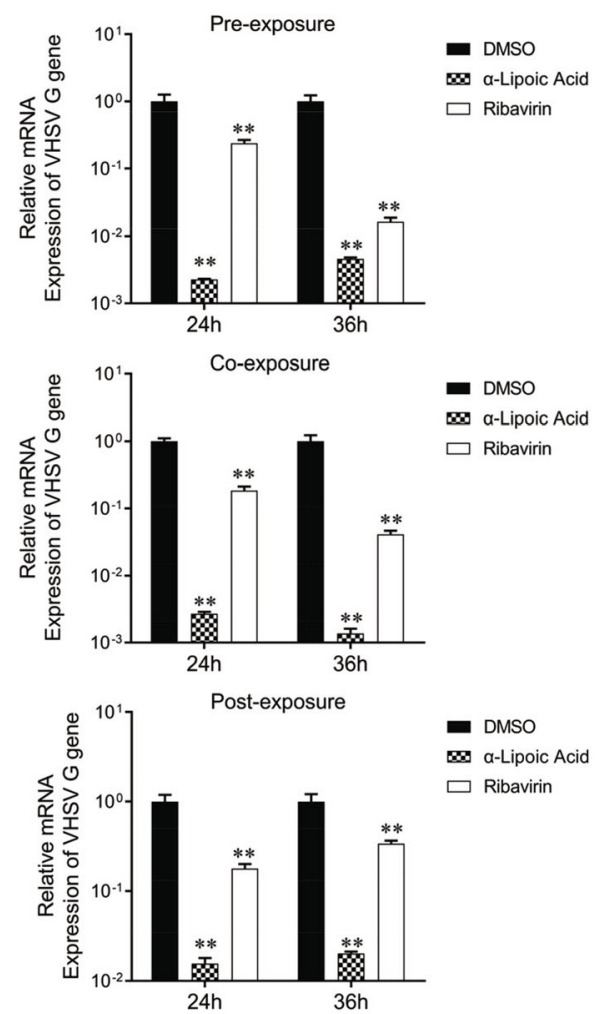

- DMSO

a-Lipoic Acid $\square$ Ribavirin

DMSO

a-Lipoic Acid $\square$ Ribavirin
Fig. 2 The antiviral activity of LA against VHSV. A The median effective concentration $\left(\mathrm{EC}_{50}\right)$ of LA was measured using CCK-8 under VHSV infection and LA treatment at $48 \mathrm{hpi}$, and calculated using GraphPad Prism 8.0.2. B The plaque staining of VHSV infected cells was conducted under LA treatment at 36 hpi with the concentration of 10, 20, 30, 40 and $50 \mu \mathrm{mol} / \mathrm{L}$. DMSO treated cells were used as the negative control. C LA exposure schemes in time-ofaddition experiment. FHM cells were infected with $10^{1.5}$ TCID $_{50}$ VHSV and treated with LA at indicated time-points, then the cells

\section{LA Treatment Reduces VHSV-Induced Oxidative Stress}

Oxidative stress plays a pivotal role in the pathogenesis of viral diseases. Multiple viruses triggered oxidative stress in infected cells to cause cell death. LA is a potent antioxidant and can reduce oxidative stress. We speculated that LA might enhance antioxidant levels in host cells to exert its antiviral effect. Firstly, we investigated whether VHSV infection could induce host oxidative stress in FHM cells. As shown in Fig. 5A, in VHSV-infected cells at $24 \mathrm{hpi}$, the were harvested at 24 hpi or 36 hpi for qRT-PCR analysis. Horizontal arrows represent the compound treatment period, triangles represent the addition of VHSV at $0 \mathrm{~h}$, vertical bars represent the end of treatments and cell collection. D The cytopathic effect (CPE) of FHM cells under DMSO, LA or ribavirin treatment at $36 \mathrm{~h}$ post VHSV infection. E The relative mRNA expression of VHSV $G$ gene in VHSV-infected FHM cells under DMSO, LA or ribavirin treatment at 24 and 36 hpi was analyzed by qRT-PCR and normalized to the level of the $\beta$-actin housekeeping gene. ${ }^{*} P<0.05$; $* * P<0.01$.

ROS, characterized by the green luciferase activity, appeared with a higher percentage than that in the negative control group, and the gene expression level of Nrf2 and SOD1 had a great upregulation (Fig. 5E and 5F), suggesting VHSV infection could induce oxidative stress. Thus, we examined the effect of oxidative stress on VHSV infection. As shown in Fig. 5C and 5D, ROS production induced by Elesclomol, an oxidative stress inducer, potentiated the replication of VHSV significantly. Furthermore, the effect of LA on VHSV-induced oxidative stress was investigated and found pre-, co-, or post- 


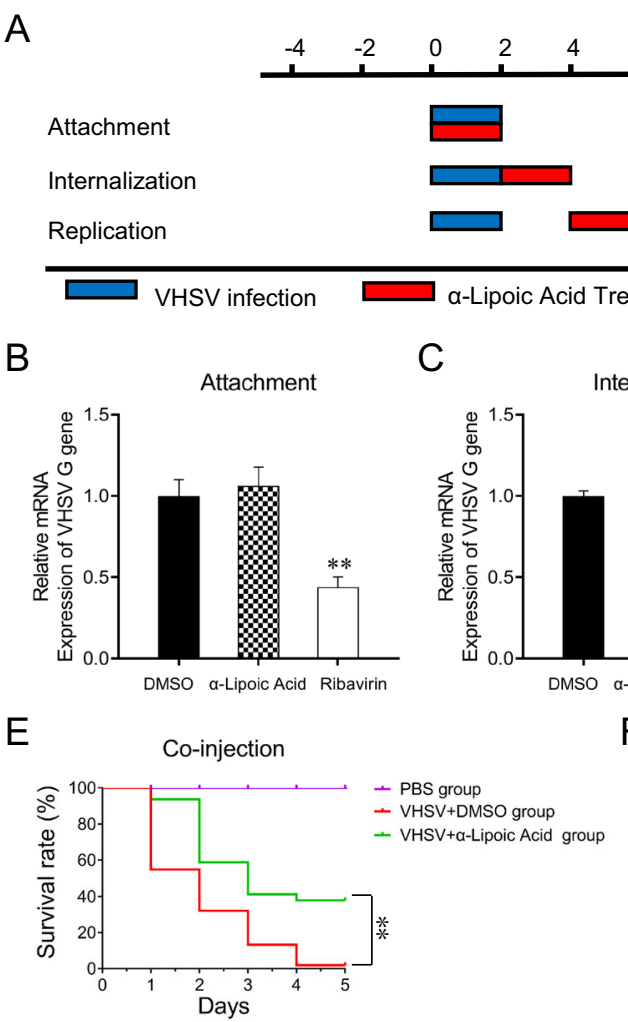

Fig. 3 Effect of LA treatment on VHSV infection cycle. A LA treatment schemes. Blue bars represent VHSV infection, red bars represent LA treatment, vertical bars represent the cell collection. BD FHM cells were infected with VHSV and treated with LA at indicated time-points (A), which represented the stage of viral attachment (B), internalization (C) or replication (D), respectively. The relative mRNA expression of VHSV $G$ gene was subsequently analyzed by qRT-PCR and normalized to the level of the $\beta$-actin housekeeping gene. E-F Survival rate of VHSV-infected largemouth

exposure of LA inhibited VHSV-induced ROS production apparently (Fig. 5B) and suppressed the upregulation of Nrf2 and SOD1 at mRNA levels (Fig. 5E and 5F). These results revealed that LA might inhibit VHSV infection by functioning as an antioxidant to reduce VHSV-induced oxidative stress.

\section{Discussion}

Drug repurposing, also referred to as drug repositioning, reinvestigate the drugs for a new application against other diseases, has generated substantial attention in recent years (Trivedi and Mohan 2020). The drugs being investigated have already been deemed with eliminated toxicity, so that drug repurposing drastically reduces the failure rate compared with designing novel drugs (Pushpakom et al. 2019). Here, 50 compounds were screened for inhibiting properties against VHSV in FHM cells, among which, LA stood out as a novel small molecular inhibitor with low bass with LA $(25 \mu \mathrm{mol} / \mathrm{L})$ treatment was conducted through intraperitoneal injection, LA or DMSO was co-injected with $20 \mu \mathrm{L}$ of VHSV $\left(10^{1.5}\right.$ TCID $\left._{50}\right)$ into largemouth bass $(\mathbf{E})$ or injected post VHSV injection at $4 \mathrm{hpi}(\mathbf{F})$, respectively. The largemouth bass injected with the same volume of PBS was used as the negative control. The survival rate of each group was calculated and the differences between the two groups were analyzed with log-rank test using the software of GraphPad Prism 8.0.2. ${ }^{*} P<0.05 ; * * P<0.01$.

cytotoxicity $\left(\mathrm{CC}_{50}=472.6 \mu \mathrm{mol} / \mathrm{L}\right)$ and potent anti-VHSV activity $\left(\mathrm{EC}_{50}=42.7 \mu \mathrm{mol} / \mathrm{L}\right)$.

LA, acting as a cellular coenzyme, was routinely used to treat diabetic polyneuropathy and hepatic disorders (Sachse and Willms 1980). Apart from that, LA has been found to exhibit antiviral effects against some viruses. Schmidt et al. found LA supplementation promoted the immune response of steers to have a more rapid recovery from IBRV challenge than others (Schmidt et al. 2006). Addition of LA attenuated the susceptibility of human cells to HCoV 229E infection (Wu et al. 2008). Herein, LA showed a dosedependent inhibition on VHSV-induced plaque, CPEs and viral gene expression in FHM cells, indicating LA had a protective effect against VHSV infection and could be repurposed as an antiviral drug. Furthermore, we tried to identify which step in VHSV growth cycle was inhibited by LA. Our results showed the addition of LA significantly decreased virus replication. The inhibitory effect of LA on the replication was also found for VACV in several cell lines, since LA significantly reduced the expression of 
A

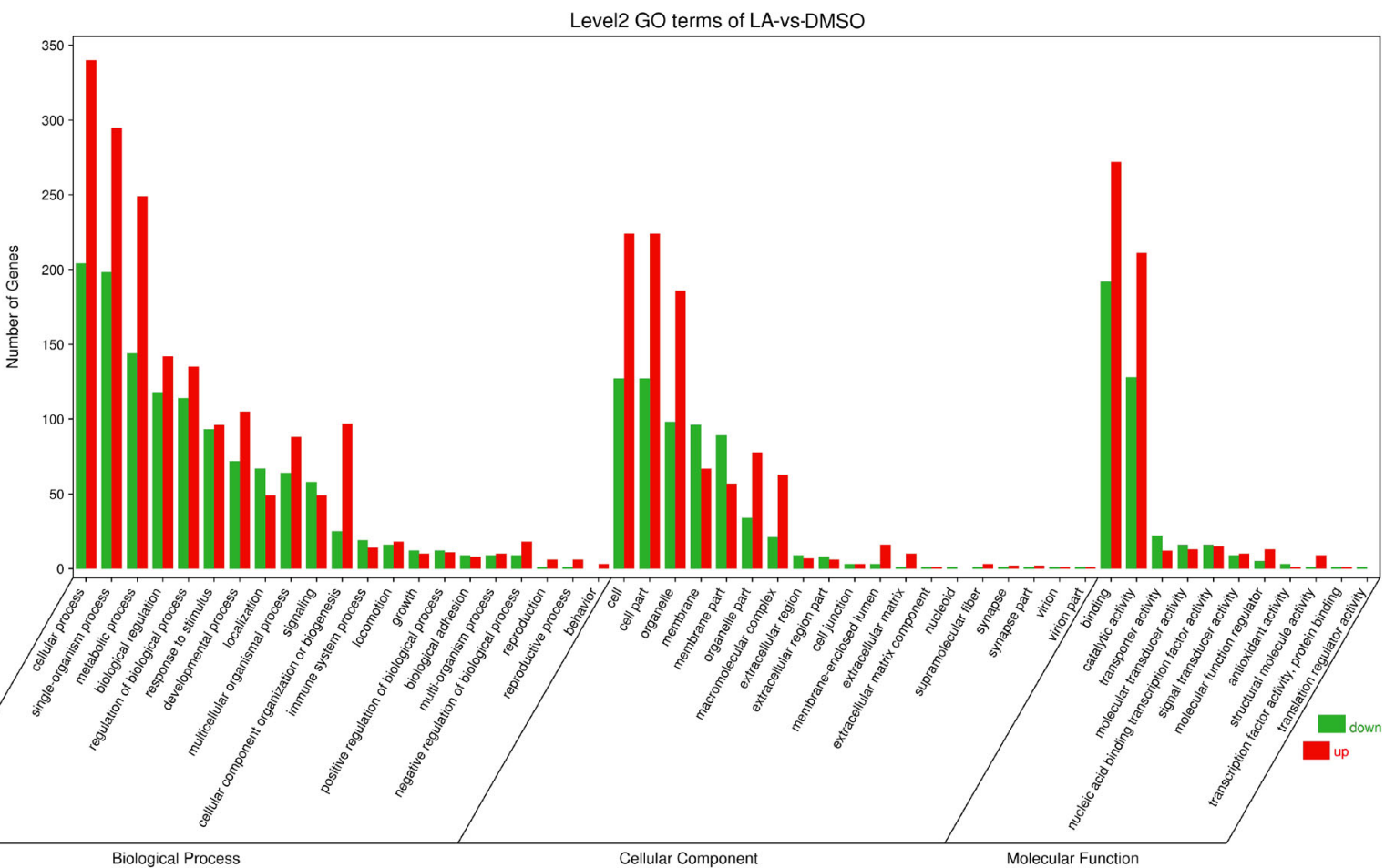

B

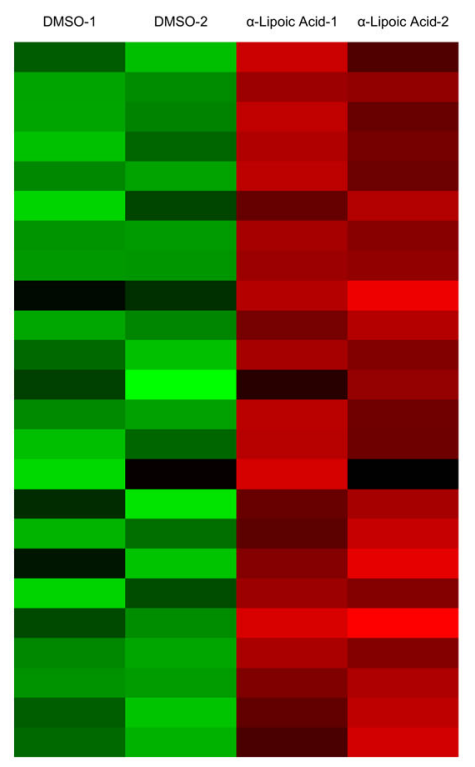

C

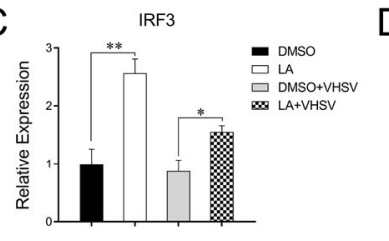

E

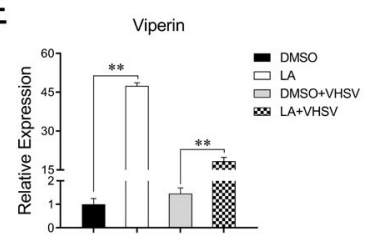

G

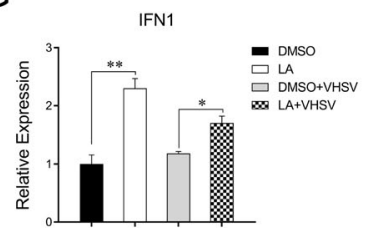

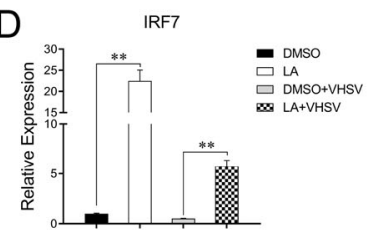

$\mathrm{F}$

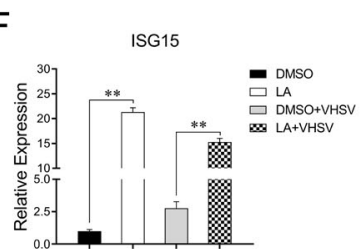

$\mathrm{H}$

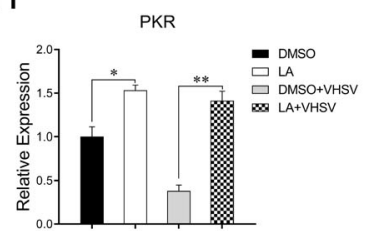

Fig. 4 Effect of LA treatment on antiviral genes expression in FHM cells. A Gene Ontology function classification of differentially expressed genes (DEGs) in transcriptomic analysis on DMSO or LA treated FHM cells with VHSV infection. B The heatmap showed some upregulated antiviral genes in LA treated FHM cells compared with the DMSO treated group, according to the fold change value of the robust rank aggregation analysis. Red indicates that DEGs are

VACV late genes but did not inhibit VACV entry or early VACV DNA synthesis (Spisakova et al. 2009). Baur et al. found the replication of HIV in T-cell lines was inhibited by LA treatment post HIV-infection acutely or chronically upregulated in LA samples compared with the DMSO samples; green indicates the opposite. C-H FHM cells were treated with DMSO or LA with or without VHSV infection, respectively. The expression level of antiviral genes, including IRF3 (C), IRF7 (D), Viperin $(\mathbf{E})$, $I S G 15(\mathbf{F}), I F N 1(\mathbf{G})$ and PKR $(\mathbf{H})$, was analyzed by qRT-PCR and normalized to the level of the $\beta$-actin housekeeping gene. ${ }^{*} P<0.05$; $* * P<0.01$.

(Baur et al. 1991). In this study, LA did not affect VHSV $G$ gene expression at the entry stage of VHSV, suggesting the inhibition of LA was irrelevant with virus entry. While, as for COVID-19, LA interfered with the entry of SARS- 
A
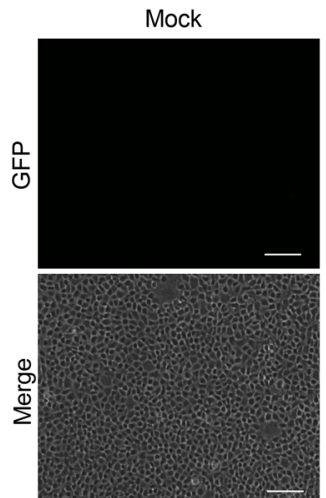

B
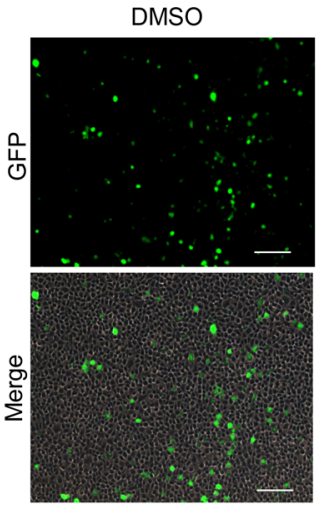

C

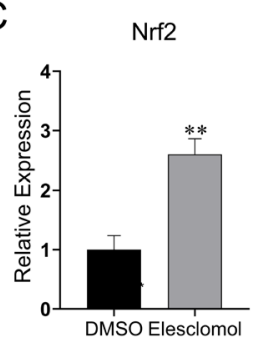

E

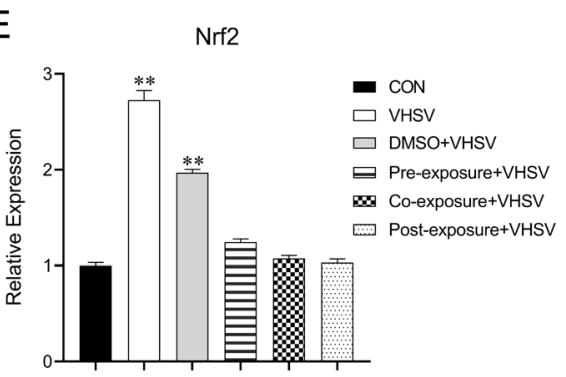

Fig. 5 LA exerted anti-oxidants role to reduce VHSV-induced oxidative stress. A FHM cells were untreated (Mock) or treated with PBS (negative), Rosup (positive), or VHSV for $24 \mathrm{~h}$, respectively. The intracellular ROS was measured with the oxidation-sensitive fluorescent probe (DCFH-DA) and observed under fluorescent microscope. The ROS production positive cells were showed with green fluorescence. GFP: green fluorescence images; Merge: the fusion image of green fluorescence signals and white-light visualization; Scale bar $=20 \mathrm{~mm}$. B FHM cells infected with VHSV were treated with DMSO or LA in pre-exposure, co-exposure, postexposure manners for $24 \mathrm{~h}$, then the intracellular ROS was measured as above. C-D FHM cells were infected with VHSV for $4 \mathrm{~h}$, and
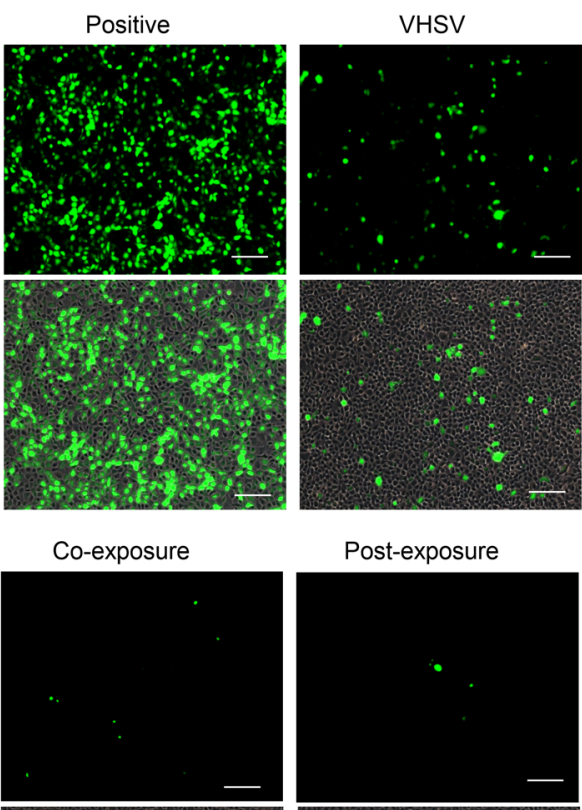

Post-exposure
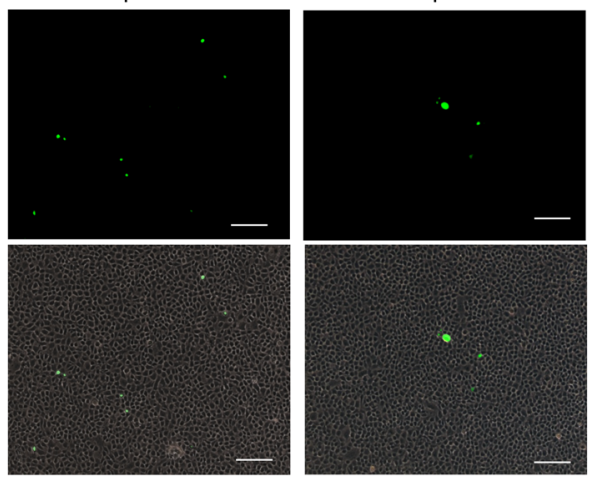

VHSV-G
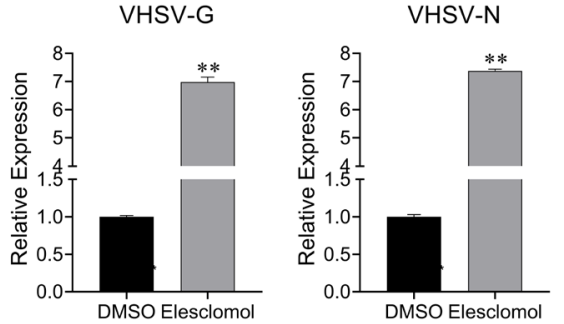

F

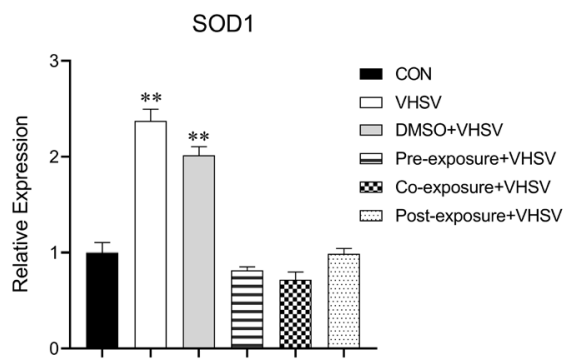

treated with Elesclomol to induce ROS production. The cells were further collected at $24 \mathrm{hpi}$ for analysis of the expression level of $\mathrm{Nrf} 2$ and SOD1 (C), VHSV $G$ and $N$ (D) by qRT-PCR. E-F The expression level of $N r f 2$ (E) and SOD1 (F) of FHM cells at different conditions were analyzed by qRT-PCR. CON, mock treatment; VHSV, VHSV infection; DMSO + VHSV, VHSV infection with DMSO treatment; pre-exposure + VHSV, VHSV infection with LA treatment in pre-exposure manner; co-exposure + VHSV, VHSV infection with LA treatment in co-exposure manner; post-exposure + VHSV, VHSV infection with LA treatment in post-exposure manners. $* P<0.05 ; * * P<0.01$. 
CoV-2 into cells by raising the intracellular $\mathrm{pH}$ through activating ATP-dependent $\mathrm{K}^{+}$channels, which further strengthened the human host defense (Cure and Cumhur Cure 2020). These findings suggested the antiviral mechanism of LA differed among various viruses, and it exerted an inhibitory effect on VHSV by interfering with the replication of VHSV. Furthermore, in vivo experiment showed that LA significantly enhanced the survival rate of VHSV-infected largemouth bass in both co-injection and post-injection manners, indicating that LA might be a promising candidate for the treatment of VHSV infection in fish. It was known that many factors might influence the antiviral effect of LA in live fish, such as administration methods (oral or injectable administration), administration dosage and so on. Thus, the relationship between the antiviral effect of LA and contributing factors will be analyzed in our future study.

Type I IFNs are an important part of the innate immune response against virus infection (Zhang and Gui 2012). Pre-activation of the IFN system could significantly inhibit the replication of fish Rhabdoviruses (Purcell et al. 2012). Considering the inhibitory effect of LA on VHSV replication, we speculated that LA might be involved in the IFN response. Additional comparative transcriptome and qRTPCR analysis revealed that several antiviral genes showed enhanced expression in LA-treated cells. IRF3 and IRF7 were characterized as antiviral factors, and they could activate the IFN gene promoter and upregulate IFN and ISGs (Cui et al. 2011; Holland et al. 2008). ISG15 was a ubiquitin homolog induced by IFN or viral infection. Knockout of ISG15 in EPC cells revealed the important role of ISG15 against VHSV infection (Kim and Kim 2019). Viperin is another IFN-stimulated antiviral protein, functioning in inhibiting virus replication (Mattijssen and Pruijn 2012). Poyntera et al. reported that enhanced Viperin and ISG15 resulted in a significant limit on VHSV infection in fathead minnow skin cells (Poynter et al. 2019). Herein, the antiviral genes stimulated by LA treatment may strengthen the FHM cell host defense against VHSV and suppress viral replication. Thus, we speculated that LA could inhibit VHSV infection in part through activating the expression of antiviral genes.

Oxidative stress was an important factor for virus infectivity, oxidative damage to cellular components would only occur when the production of ROS exceeded the cell's antioxidant capacity (Krapfenbauer et al. 2003). Many viruses could trigger oxidative stress and induce ROSmediated cell death to facilitate virus replication, including red-spotted grouper nervous necrosis virus (Chang et al. 2011), HBV (Vierucci et al. 1983) and HIV (Müller 1992). Here, we found that VHSV infection induced ROS production and upregulated the expression of $\mathrm{Nrf} 2$ and SOD1,

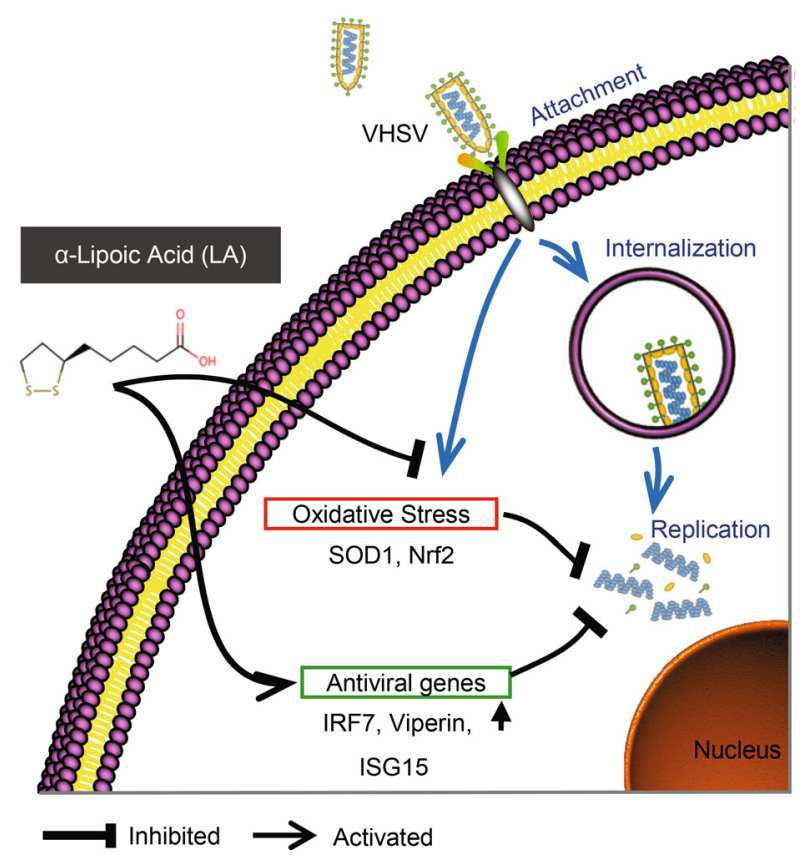

Fig. 6 Scheme summarizing the inhibitory effect of LA on VHSV replication via activation of antiviral genes and suppression of VHSVinduced oxidative stress.

which were antioxidant transcription factors and could protect against the deleterious effects of oxidative stress via regulating the transcriptional activation of various antioxidant biomolecules (Kaspar et al. 2009). Correspondingly, ROS production induced by Elesclomol significantly increased the replication of VHSV, suggesting VHSV infection triggered the oxidative stress in FHM cells to facilitate its replication. LA, as a universal antioxidant, was involved in scavenging free radicals to protect against oxidative damage in some diseases (Tibullo et al. 2017). By reducing oxidative stress, LA exerted an antiviral effect against several viruses, for example, the addition of LA modulated total glutathione (GSH + GSSG) levels and ameliorated HIV-induced redox-stress in HIV-infected subjects (Baur et al. 1991). Here, LA treatment markedly reduced VHSV-generated ROS and suppressed VHSV-induced expression of $\mathrm{Nrf} 2$ and $S O D 1$ in pre-, co- or postexposure manner, indicating the protective effect of LA against VHSV could be due to its antioxidant role in reducing oxidative stress.

In conclusion, the present study identifies LA as a promising candidate of the anti-VHSV compound, activating antiviral genes and suppressing host cellular oxidative stress to inhibit VHSV infection (Fig. 6). This finding offers a new potent antiviral compound for combating infections caused by VHSV. 
Acknowledgements This work was supported by the Pearl River S\&T Nova Program of Guangzhou (201806010047), the National Natural Science Foundation of China (31771587), and Fundamental Research Funds for the Central Universities.

Author Contributions All authors contributed to the study conception and design. KJ, MY and WZ designed this research. WZ, XC, FY, WL and FL conducted the research; WZ, KJ, FL wrote the first draft of the manuscript. FY, MY and KJ revised the manuscript. All authors read and approved the final manuscript.

\section{Compliance with Ethical Standards}

Conflict of interest The authors declare that they have no conflict of interest.

Human and Animal Rights All animal experiments procedures were approved by the Ethics Committee of Sun Yat-Sen University and were carried out following the approved guidelines.

\section{References}

Balmer BF, Getchell RG, Powers RL, Lee J, Zhang T, Jung ME, Purcell MK, Snekvik K, Aguilar HC (2018) Broad-spectrum antiviral JL122 blocks infection and inhibits transmission of aquatic rhabdoviruses. Virology 525:143-149

Baur A, Harrer T, Peukert M, Jahn G, Kalden JR, Fleckenstein B (1991) Alpha-lipoic acid is an effective inhibitor of human immuno-deficiency virus (HIV-1) replication. Klin Wochenschr 69:722-724

Bloom BE (2015) Creating new economic incentives for repurposing generic drugs for unsolved diseases using social finance. Assay Drug Dev Technol 13:606-611

Chang CW, Su YC, Her GM, Ken CF, Hong JR (2011) Betanodavirus induces oxidative stress-mediated cell death that prevented by anti-oxidants and zfcatalase in fish cells. PLoS One 6:25853

Cui H, Yan Y, Wei J, Huang X, Huang Y, Ouyang Z, Qin Q (2011) Identification and functional characterization of an interferon regulatory factor 7-like (IRF7-like) gene from orange-spotted grouper, Epinephelus coioides. Dev Comp Immunol 35:672-684

Cure E, Cumhur Cure M (2020) Alpha-lipoic acid may protect patients with diabetes against COVID-19 infection. Med Hypotheses 143:110185

Dyall J, Coleman CM, Hart BJ, Venkataraman T, Holbrook MR, Kindrachuk J, Johnson RF, Olinger GG, Jahrling PB, Laidlaw M, Johansen LM, Lear-Rooney CM, Glass PJ, Hensley LE, Frieman MB (2014) Repurposing of clinically developed drugs for treatment of middle east respiratory syndrome coronavirus infection. Antimicrob Agents Chemother 58:4885-4893

Gomez-Casado E, Estepa A, Coll JM (2011) A comparative review on European-farmed finfish RNA viruses and their vaccines. Vaccine 29:2657-2571

Hernandez JJ, Pryszlak M, Smith L, Yanchus C, Kurji N, Shahani VM, Molinski SV (2017) Giving drugs a second chance: overcoming regulatory and financial hurdles in repurposing approved drugs as cancer therapeutics. Front Oncol 7:273

Hiller S, Dekroon R, Hamlett ED, Xu L, Osorio C, Robinette J, Winnik W, Simington S, Maeda N, Alzate O (2016) Alpha-lipoic acid supplementation protects enzymes from damage by nitrosative and oxidative stress. Biochimica et Biophysica Acta General Subjects 1860:36-45

Holland JW, Bird S, Williamson B, Woudstra C, Mustafa A, Wang T, Zou J, Blaney SC, Collet B, Secombes CJ (2008) Molecular characterization of IRF3 and IRF7 in rainbow trout, Oncorhynchus mykiss: functional analysis and transcriptional modulation. Mol Immunol 46:269-285

Hørlyck V, Mellergård S, Dalsgaard I, Jørgensen PEV (1984) Occurrence of VHS in Danish maricultured rainbow trout. Bull Eur Assoc Fish Pathol 4:11-13

Jeong EH, Vaidya B, Cho SY, Park MA, Kaewintajuk K, Kim SR, Oh MJ, Choi JS, Kwon J, Kim D (2015) Identification of regulators of the early stage of viral hemorrhagic septicemia virus infection during curcumin treatment. Fish Shellfish Immunol 45:184-193

Kamiyama N, Soma R, Hidano S, Watanabe K, Umekita H, Fukuda C, Noguchi K, Gendo Y, Ozaki T, Sonoda A, Sachi N, Runtuwene LR, Miura Y, Matsubara E, Tajima S, Takasaki T, Eshita Y, Kobayashi T (2017) Ribavirin inhibits Zika virus (ZIKV) replication in vitro and suppresses viremia in ZIKVinfected STAT1-deficient mice. Antiviral Res 146:1-11

Kang SY, Kang JY, Oh MJ (2012) Antiviral activities of flavonoids isolated from the bark of Rhus verniciflua stokes against fish pathogenic viruses In Vitro. J Microbiol 50:293-300

Kaspar JW, Niture SK, Jaiswal AK (2009) Nrf 2:INrf2 (Keap1) signaling in oxidative stress. Free Radic Biol Med 47:1304-1309

Kesselheim AS, Tan YT, Avorn J (2015) The roles of academia, rare diseases, and repurposing in the development of the most transformative drugs. Health Aff (millwood) 34:286-293

Kim MS, Kim KH (2019) Effect of CRISPR/Cas9-mediated knockout of either Mx1 or ISG15 gene in EPC cells on resistance against VHSV infection. Fish Shellfish Immunol 93:1041-1046

Krapfenbauer K, Engidawork E, Cairns N, Fountoulakis M, Lubec G (2003) Aberrant expression of peroxiredoxin subtypes in neurodegenerative disorders. Brain Res 967:152-160

Kütter MT, Monserrat JM, Primel EG, Caldas SS, Tesser MB (2012) Effects of dietary $\alpha$-lipoic acid on growth, body composition and antioxidant status in the Plata pompano Trachinotus marginatus (Pisces, Carangidae). Aquaculture 368-369:29-35

Linck DW, Larman MG, Gardner DK (2007) a alpha-lipoic acid: an antioxidant that improves embryo development and protects against oxidative stress. Fertil Steril 88:S36-S37

Marroqui L, Estepa A, Perez L (2007) Assessment of the inhibitory effect of ribavirin on the rainbow trout rhabdovirus VHSV by real-time reverse-transcription PCR. Vet Microbiol 122:52-60

Mattijssen S, Pruijn GJ (2012) Viperin, a key player in the antiviral response. Microbes Infect 14:419-426

Miao Y, Ren J, Jiang L, Liu J, Jiang B, Zhang X (2013) alpha-Lipoic acid attenuates obesity-associated hippocampal neuroinflammation and increases the levels of brain-derived neurotrophic factor in ovariectomized rats fed a high-fat diet. Int $\mathrm{J}$ Mol Med 32:1179-1186

Monserrat JM, Lima JV, Ferreira JLR, Acosta D, Garcia ML, Ramos PB, Moraes TB, Dos Santos LC, Amado LL (2008) Modulation of antioxidant and detoxification responses mediated by lipoic acid in the fish Corydoras paleatus (Callychthyidae). Comp Biochem Physiol c: Toxicol Pharmacol 148:287-292

Moya J, Pizarro H, Jashés M, Clercq ED, Sandino AM (2000) In vivo effect of EICAR (5-ethynyl-1- $\beta$-d-ribofuranosylimidazole-carboxamide) on experimental infected rainbow trout ( Oncorhynchus mykiss ) and coho salmon ( Oncorhynchus kisutch ) fry with infectious pancreatic necrosis virus. Antiviral Res 48:125-130

Müller F (1992) Reactive oxygen intermediates and human immunodeficiency virus (HIV) infection. Free Radic Biol Med 13:651-657

Novac N (2013) Challenges and opportunities of drug repositioning. Trends Pharmacol Sci 34:267-272

Novotny L, Rauko P, Cojocel C (2008) alpha-lipoic acid: the potential for use in cancer therapy. Neoplasma 55:81-86 
Park KH, Terjesen BF, Tesser MB, Portella MC, Dabrowski K (2006) $\alpha$-Lipoic acid-enrichment partially reverses tissue ascorbic acid depletion in pacu (Piaractus mesopotamicus) fed vitamin C-devoid diets. Fish Physiol Biochem 32:329-338

Park YJ, Moon C, Kang JH, Choi TJ (2017) Antiviral effects of extracts from Celosia cristata and Raphanus sativus roots against viral hemorrhagic septicemia virus. Arch Virol 162:1711-1716

Pereiro P, Figueras A, Novoa B (2016) Turbot (Scophthalmus maximus) vs. VHSV (Viral Hemorrhagic Septicemia Virus): a review. Front Physiol 7:192

Pham PH, Sokeechand BSH, Hamilton ME, Misk E, Jones G, Lee LEJ, Lumsden JS, Bols NC (2019) VER-155008 induced Hsp70 proteins expression in fish cell cultures while impeding replication of two RNA viruses. Antiviral Res 162:151-162

Poynter SJ, Leis EM, Dewitte-Orr SJ (2019) In vitro transcribed dsRNA limits viral hemorrhagic septicemia virus (VHSV)-IVb infection in a novel fathead minnow (Pimephales promelas) skin cell line. Fish Shellfish Immunol 86:403-409

Purcell MK, Laing KJ, Winton JR (2012) Immunity to Fish Rhabdoviruses. Viruses 4:140-166

Pushpakom S, Iorio F, Eyers PA, Escott KJ, Hopper S, Wells A, Doig A, Guilliams T, Latimer J, Mcnamee C, Norris A, Sanseau P, Cavalla D, Pirmohamed M (2019) Drug repurposing: progress, challenges and recommendations. Nat Rev Drug Discovery $18: 41-58$

Reed LJ (1974) Multienzyme complexes. Acc Chem Res 7:40-46

Ross K, Mccarthy U, Huntly PJ, Wood BP, Stuart D, Rough EI, Smail DA, Bruno DW (1995) A outbreak of viral haemorrhagic septicaemia (VHS) in turbot (Scophthalmus maximus) in Scotland. Bull Eur Assoc Fish Pathol 14:213-214

Sachse G, Willms B (1980) Efficacy of thioctic acid in the therapy of peripheral diabetic neuropathy. Horm Metab Res Suppl 9:105-107

Sariyer IK, Gordon J, Burdo TH, Wollebo HS, Gianti E, Donadoni M, Bellizzi A, Cicalese S, Loomis R, Robinson JA, Carnevale V, Steiner J, Ozdener MH, Miller AD, Amini S, Klein ML, Khalili $\mathrm{K}$ (2019) Suppression of zika virus infection in the brain by the antiretroviral drug rilpivirine. Mol Ther 27:2067-2079

Schmidt TB, Brown MS, Larson RL, Kleiboeker SB, Olson KC, Keisler D, Carroll JA, Berg EP (2006) Effect of dietary lipoic acid on metabolic hormones and acute-phase proteins during challenge with infectious bovine rhinotracheitis virus in cattle. Am J Vet Res 67:1192-1198

Schütze H, Mundt E, Mettenleiter TC (1999) Complete genomic sequence of viral hemorrhagic septicemia virus, a fish rhabdovirus. Virus Genes 19:59-65

Selvakumar E, Hsieh TC (2008) Regulation of cell cycle transition and induction of apoptosis in HL-60 leukemia cells by lipoic acid: role in cancer prevention and therapy. $\mathrm{J}$ Hematol Oncol 1:4

Spisakova M, Cizek Z, Melkova Z (2009) Ethacrynic and alpha-lipoic acids inhibit vaccinia virus late gene expression. Antiviral Res 81:156-165

Tibullo D, Li Volti G, Giallongo C, Grasso S, Tomassoni D, Anfuso CD, Lupo G, Amenta F, Avola R, Bramanti V (2017) Biochemical and clinical relevance of alpha lipoic acid: antioxidant and anti-inflammatory activity, molecular pathways and therapeutic potential. Inflamm Res 66:947-959

Trivedi J, Mohan M (2020) Drug repurposing approaches to combating viral infections. J Clin Med 9:3777

Vierucci A, De Martino M, Graziani E, Rossi ME, London WT, Blumberg BS (1983) A mechanism for liver cell injury in viral hepatitis: effects of hepatitis B virus on neutrophil function in vitro and in children with chronic active hepatitis. Pediatr Res 17:814-820

Wu YH, Tseng CP, Cheng ML, Ho HY, Shih SR, Chiu DT (2008) Glucose-6-phosphate dehydrogenase deficiency enhances human coronavirus 229E infection. J Infect Dis 197:812-816

Yang HK, Jung MH, Avunje S, Nikapitiya C, Kang SY, Ryu YB, Lee WS, Jung SJ (2018) Efficacy of algal Ecklonia cava extract against viral hemorrhagic septicemia virus (VHSV). Fish Shellfish Immunol 72:273-281

Zhang WJ, Frei B (2001) Alpha-lipoic acid inhibits TNF-alphainduced NF-kappaB activation and adhesion molecule expression in human aortic endothelial cells. FASEB J 15:2423-2432

Zhang YB, Gui JF (2012) Molecular regulation of interferon antiviral response in fish. Dev Comp Immunol 38:193-202

Zhang W, Li Z, Xiang Y, Jia P, Liu W, Yi M, Jia K (2019) Isolation and identification of a viral haemorrhagic septicaemia virus (VHSV) isolate from wild largemouth bass Micropterus salmoides in China. J Fish Dis 42:1563-1572 